\title{
UMA PONTE PARA A URBANIDADE
}

\author{
FREDERICO DE H OLANDA
}

R E S U M O Este trabalho explora procedimentos analiticos quantitativos para caracterizar três tipos de atributos morfológicos da capital brasileira. Primeiro, o Plano Piloto não é central em face do sistema urbano maior ao qual de fato pertence e, contrariando os pressupostos colocados por Lúcio Costa no memorial do projeto de Brasilia, ele já nasceu excêntrico. Segundo, trata-se de um sistema extremamente disperso, o que é caracterizado aqui por meio de duas medidas alternativas de compacidade. Terceiro, há uma fortíssima segregação socioespacial, caracterizada pelas fracas correlaçōes obtidas entre localização de empregos, localização de habitaçôes, e acessibilidade fisica: não apenas a grande maioria dos empregos também é excêntrica (pois mais de 70\% deles estão no Plano Piloto), como a grande maioria dos moradores concentra-se nas partes mais segregadas da cidade. Ao final do trabalho, especula-se medidas que implicam maior urbanidade para a Capital Federal. ${ }^{1}$

P A L A V R A S - C H A V E Brasilia; centralidade; compacidade; segregação social; sintaxe espacial; desenho urbano; urbanidade.

\section{NTRODUÇÃO}

Este trabalho procura contribuir para o entendimento da forma urbana da capital brasileira - Brasília. Utilizamos procedimentos analíticos para trabalhar três aspectos desta forma: 1) a maneira pela qual o Plano Piloto - a parte da cidade originalmente proposta por Lúcio Costa por ocasião do concurso público de 1957 - relaciona-se com o resto do sistema urbano onde está de fato inserido, particularmente em termos de sua relativa centralida$d e$; 2) a maneira pela qual esta cidade - toda a cidade real, não apenas o Plano Piloto - se espalha pelo território, utilizando-se para tanto duas medidas alternativas de compacidade; 3) a maneira como se distribuem, no espaço, empregos e moradias, caracterizando-se a relativa segregação de ambas instâncias, tanto entre si, como em termos das características configuracionais dos lugares em que se situam, no sentido de sua acessibilidade à cidade inteira.

As questôes de centralidade e compacidade são examinadas historicamente, em cortes decenais, desde a inauguração da cidade. Para a questão da segregação relativa de empregos e moradias, estudamos um momento específico, lançando mão dos dados cartográficos e demográficos mais recentes. Metodologicamente, utilizamos tanto conceitos e técnicas tradicionais da teoria da sintaxe espacial, ${ }^{2}$ como categorias analíticas sugeridas por outros autores (por exemplo, Bertaud \& Malpezzi, 1999), e ainda experimentamos procedimentos metodológicos originais.

Há uma literatura crescentemente disponível sobre a forma da cidade brasileira, com preocupações semelhantes às expostas aqui (por exemplo, em Rigatti, 1997; Loureiro \& Amorim, 2000; Trigueiro et al., 2001, respectivamente para os casos de Porto Alegre,

1 As idéias aqui expostas foram exploradas preliminarmente em Mota et al. (2000). A presente versão reflete 0 estágio atual (setembro de 2002) de trabalho desenvolvido no âmbito do Projeto de Pesquisa apoiado pelo $\mathrm{CNPq}$, intitulado Forma e uso do espaço urbano: a estrutura urbana do Distrito Federal, Brasil, de responsabilidade do autor. Explora, pela primeira vez, o índice de dispersão; outros aspectos, antes abordados, são aqui aprofundados. 0 autor agradece a colaboração de George Alex da Guia, no processamento de informações e na preparação das ilustrações, e os comentários de Claudia Loureiro, Cláudia Garcia, Franciney França e Rômulo Ribeiro, a uma versão preliminar deste texto.

2 A teoria da sintaxe espacial foi proposta inicialmente por Bill Hillier e outros colegas da Bartlett School of Graduate Studies (Hillier \& Hanson, 1984), de Londres, e desenvolvida posteriormente por pesquisadores em várias partes do mundo, inclusive em diversas universidades brasileiras, como se indica na bibliografia. Visa basicamente a compreensão das relações entre a configuração de cidades e edifícios, e a maneira pela qual as pessoas usam e se movem ao longo de seus espaços. 
3 Estes aspectos foram examinados mais detalhadamente noutra oportunidade, em Holanda, 2002. Ver também a análise de Matheus Gorovitz, em Brasilia, uma questão de escala (1985).

4 Ver Machado \& MagaIhães, "Imagens do espaço: imagens de vida", 1985.

5 Ver, em termos gerais, como Lúcio Costa se colocava ideologicamente: "Não sou capitalista nem socialista, não sou religioso nem ateu -, acredito simplesmente na minha velha teoria das resultantes convergentes" (1995, p.598).
Recife e Natal). Este trabalho pretende somar-se a tais esforços, quem sabe estimulando uma experimentação coletiva no teste de procedimentos analíticos, e contribuindo para uma taxonomia da forma urbana brasileira.

Cabe ainda observar que a abordagem crítica sobre vários aspectos de Brasília, tanto relativa à sua situação atual, como relativa ao seu projeto original, não implica o desconhecimento de sua importância. Constituiu indiscutivelmente a melhor proposta entre todas aquelas apresentadas por ocasião do concurso para o Plano Piloto. Mais do que isso, trata-se de uma cidade exemplar não somente por fixar indelevelmente o seu tempo (é claramente concebida e realizada no século XX) mas pelo fato de Lúcio Costa ter aplicado de maneira própria o "receituário modernista" (até transgredindo-o em alguns pontos), e por ter sabiamente incorporado elementos fundamentais da história do urbanismo de todos os tempos: as perspectivas barrocas, os terraplenos monumentais, o gregarismo colonial brasileiro, a acrópole cerimonial, a cidade-linear, a cidade-jardim, a urbanidade dos comércios locais etc. ${ }^{3}$ Em outras palavras, uma cidade "pós-moderna" avant la lettre... Nisso reside sua força, que a distingue de todas as demais manifestações da modernidade urbanística. Mas é exatamente o respeito que Brasília impõe que exige seu exame rigoroso, por meio de uma visão crítica que somente a distância no tempo, assim como o desenvolvimento teórico e prático da arquitetura ao longo dessas décadas de sua existência permitem. Essa a tentativa deste texto.

\section{DISCURSO E REALIDADE}

Há um razoável consenso de que a segregação socioespacial no Distrito Federal no Brasil, onde Brasília se localiza, é extremamente "perversa", impondo altos custos sociais para as faixas de renda mais baixas. Entretanto, há pouca, ou quase nenhuma, concordância quanto ao grau em que tal "perversidade" está implicada no próprio projeto de Lúcio Costa. Argumenta-se que simplesmente encontramos aqui a segregação socioespacial característica da sociedade brasileira em geral. ${ }^{4}$ Evidentemente, tal segregação está fundamentalmente relacionada a uma sociedade extremamente desigual. Mas não avançaremos no domínio do nosso próprio ofício - de arquitetos, no caso - se não procurarmos entender melhor a medida em que o próprio desenho pode implicar exclusão. A discussão que se segue procura dar uma contribuição neste sentido.

Houve, de fato, uma intenção declarada de não-segregação, por parte de Lúcio Costa, citada à exaustão pela literatura como evidência da natureza democrática, "socialista" até, do projeto, embora o próprio Lúcio Costa talvez nunca tivesse feito uso desta expressão em relação à cidade. ${ }^{5}$ Certamente não, pelo menos, na Memória descritiva do Plano Piloto, de 1957. Recordemos o seguinte trecho:

A gradação social poderá ser dosada facilmente atribuindo-se maior valor a determinadas quadras (...) as quadras contíguas à rodovia serão naturalmente mais valorizadas que as quadras internas, o que permitirá as gradaçôes próprias do regime vigente: contudo o agrupamento delas, de quatro em quatro, propicia num certo grau a coexistência social, evitando-se assim uma indevida e indesejável estratificação [grifo nosso] (...) Neste sentido deve-se impedir a enquistação de favelas tanto na periferia urbana quanto na rural [grifo nosso]. Cabe à Companhia Urbanizadora prover dentro do esquema proposto acomodaçôes decentes e econômicas para a totalidade [grifo no original] da população. (Costa, 1995, p.293.) 
Entretanto, a contradição entre o ser da cidade brasileira (como ela de fato se estruturava naquele momento) e o seu dever ser (como concebido pelo projeto) logo se revelaria. Os milhares de trabalhadores atraídos para o Distrito Federal pela construção da Capital não tiveram acesso aos tipos edilícios propostos no Plano Piloto. No Brasil, como em todo o mundo, a urbanização da população migrante é um longo processo no tempo, iniciando-se com os mais elementares abrigos, que vão passando por melhorias progressivas na medida das possibilidades crescentes (quando o caso) das pessoas que os constroem. Esse processo real não foi contemplado pela proposta do Plano Piloto: tipos edilícios diferentes dos blocos sobre pilotis e com elevadores, ou das "casas individuais" próximas à margem do lago, não eram admitidos no projeto (cedo novos tipos foram acrescentados, mas que não mudaram essencialmente o repertório).

Se não havia condições políticas e/ou econômicas para proporcionar "acomodações decentes" para a totalidade da população, dentro das condiçôes do mercado formal ou dos programas governamentais, como queria Lúcio Costa, algum outro modo de produção do espaço habitacional - o que implicava igualmente uma diferente tipologia edilícia - teria de ser considerado. E o foi, porém fora do Plano Piloto. Para resumir uma longa história de conflitos e reivindicaçóes (Codeplan, 1984b), já em 1958 o projeto de uma nova cidade - Taguatinga, a $20 \mathrm{~km}$ do Plano Piloto - era implantado, com lotes (não edificados) vendidos aos trabalhadores a preços acessíveis e a longo prazo. Taguatinga antecipou-se, portanto, à inauguração da nova capital. Lúcio Costa iria depois manifestar-se em relação a essa antecipação das cidades-satélites, no item 7 ("Características Fundamentais do Plano Piloto") do documento Brasília Revisitada:

A implantação de Brasília partiu do pressuposto que sua expansão se faria através de cidades-satélites, e não da ocupação gradativa das áreas contíguas ao núcleo original (...) Assim, a partir do surgimento precoce das cidades-satélites, prevaleceu agora a intenção de manter entre estes núcleos e a capital uma larga faixa verde, destinada a uso rural (...) Tal abordagem teve como conseqüência positiva a manutenção, ao longo de todos esses anos, da feição original de Brasilia. Mas, em contrapartida, a longa distância entre as satélites e o "Plano Piloto" isolou demais a matriz dos dois terços de sua população metropolitana que reside nos núcleos periféricos, além de gerar problemas de custo para transporte coletivo. (Costa, 1987, p.7, grifos nossos.)

E, na "Conclusão" desse mesmo documento, afirmou:

A Brasilia não interessa ser grande metrópole (...) Brasília é a expressão de um determinado conceito urbanístico, tem filiação certa, não é uma cidade bastarda. (Costa, 1987, p.18, grifos do original.)

O rumo que tomou o desenvolvimento da capital, diferente do previsto, fez Lúcio Costa lastimar os altos custos sociais envolvidos, assunto ao qual voltou repetidas vezes: criticou a construção de um mesmo padrão de apartamentos, "sem que fossem atendidas as três faixas econômicas em que se decompõe, grosso modo, no mundo capitalista, a população que trabalha na administração pública e na empresa privada", 6 "como se a sociedade atual já fosse sem classes"; ${ }^{7}$ a explicação para se ter ignorado sua proposição de construir moradia para diferentes níveis de poder aquisitivo estaria nos "vícios de uma 
8 Idem, p.315

9 Idem, ibidem.

10 Idem, p.320, grifos do original. trato com os empregados, sempre os mantinham à distância" . Entretanto, imediatamente acrescentou que isto "não teria resolvido o problema, já que grande parte da população trabalhadora é ainda menos do que pobre", ${ }^{9}$ pelo que ele reconhecia que muita gente não teria mesmo acesso à tipologia edilícia do Plano Piloto.

Isto não levou Lúcio Costa a reavaliar os padrões espaciais originalmente propostos, seja quanto às características do próprio Plano Piloto, seja quanto às suas relações com as demais cidades do Distrito Federal: a manutenção da "feição original de Brasília", assim como de um "determinado conceito urbanístico", tiveram primazia. Continuou acreditando na proposta originalmente concebida, porque

teria sido pior que tolice - um crime - planejar a cidade na medida da realidade subdesenvolvida atual (...) como no capitalismo ou socialismo, a tendência universal - apesar da contestação desbragada e romântica - é todo mundo virar, pelo menos, classe média, o chamado Plano Piloto pode ser considerado uma antecipação. Assim, na realidade futura, quando lá chegarmos, todos indistintamente se sentirão ambientados no aconchego antigo e condigno da "velha capital". ${ }^{10}$

O problema é que a população constituinte desta "realidade subdesenvolvida" era, e continua sendo, a grande maioria. A ela correspondiam outros modos de produção, assim como outra configuração do espaço habitacional. Admiti-los constituía uma condição necessária para a não-segregação da população mais pobre naqueles momentos iniciais. Negá-los, em nome de um "determinado conceito urbanístico" constituía, concretamente, uma exclusão pelo projeto.

Evidentemente, seria um grande equívoco acreditar que apenas o desenho da cidade, qualquer que fosse, seria condição suficiente para evitar a segregação socioespacial: além do desenho, esta segregação está relacionada a modos de gestão do espaço urbano, assim como a fatores socioeconômicos mais gerais, como assimetrias de renda e de poder - entre as maiores do mundo, no Brasil. Se não por outras razões, somente a valorização dos imóveis, pela maior proximidade a empregos e serviços, seria responsável pela mudança da população mais pobre para áreas mais afastadas.

Ainda assim, a pequena medida em que foram produzidas habitações mais econômicas dentro do Plano Piloto, implicando pequenas concessões em face dos princípios do projeto - a exemplo dos edifícios de apartamentos de três pavimentos, sem pilotis ou elevadores, em algumas quadras “ 400 ” na Asa Sul - contribuiu para a permanência aqui, até hoje, de uma parcela de população de renda bem inferior àquela de quem mora nas superquadras mais valorizadas. Maiores concessões, em termos de modos de produção e configuração, como comentado, teriam implicado maior inclusão.

Portanto, a segregação socioespacial poderia ter assumido características menos extremas. Considerados todos os aspectos do processo de produção do espaço urbano, a segregação no Distrito Federal também se deu em função da proposta original, e não somente apesar dela. Fatores especificamente morfológicos contribuíram para que a Brasília projetada constituísse, desde a origem, uma parte menor e fisicamente excêntrica, em face da cidade inteira da qual faz parte. Veremos a seguir como as categorias analíticas utilizadas neste trabalho permitem enxergar com mais precisão este processo. 


\section{CENTRALIDADE}

A técnica de axialidade, da teoria da sintaxe espacial, já referida, permite reduzir um sistema urbano a um conjunto de segmentos de reta que, da maneira mais aproximadamente possível, correspondam aos eixos de ruas ou estradas (Holanda, 2002). Por meio de procedimentos computacionais que utilizam o programa Axman (Dalton, s.d.), revela-se a medida de integração de cada eixo, que indica numericamente sua relativa acessibilidade em face do sistema inteiro. Essa acessibilidade, entretanto, é mais de ordem topológica do que geométrica, ou seja, tem por referência a quantidade mínima de linhas intervenientes que temos de percorrer entre cada uma delas e todas as outras. $\mathrm{O}$ conjunto de eixos urbanos mais acessíveis a partir do sistema inteiro é chamado de núcleo integrador, e constitui, neste trabalho, o que consideramos o centro morfológico da cidade, ou seja, aquela parte que é mais acessível fisicamente a todas as outras. ${ }^{11}$

Num primeiro momento, analisaremos os mapas axiais que consideram apenas as rodovias e vias arteriais do sistema. Não dispomos de informações detalhadas que permitam a análise de todas as vias urbanas ao longo da história da cidade, mas os mapas rodoviários estudados constituem uma aproximação razoável para identificar as principais características da macroestrutura urbana.

Em 1960, além de Taguatinga, já citada, foram criadas mais duas novas cidadessatélites, localizadas em direções opostas: Sobradinho e Gama a $25 \mathrm{~km}$ a nordeste, e a 38 km a sudoeste de Brasília, respectivamente. A situação em 1960 está registrada na Figura 1. Incluem-se Taguatinga, Gama e Sobradinho, mas excluem-se Brazlândia e Planaltina, por constituírem, estes últimos, núcleos preexistentes a Brasília, e por não terem tido, até então, nenhum novo acréscimo em suas áreas urbanas. $\mathrm{O}$ processamento deste primeiro mapa $^{12}$ revela que o centro topológico do sistema já se localizava, naquela época, fora de Brasília, na periferia oeste do Plano Piloto. Essa excentricidade apenas se confirma com o acréscimo de novos núcleos: ainda nos anos 1960, o Guará-I; nos anos 1970, Ceilândia e Guará-II; nos anos 1980, Samambaia; nos anos 1990, Santa Maria, São Sebastião, Riacho Fundo e Recanto das Emas (por razões de espaço, incluímos apenas os mapas correspondentes a 1960 - Figura 1, e 1998 - Figura 2)..$^{13}$

Como comentamos acima, não temos informações precisas, ao longo das décadas passadas, sobre o conjunto total de vias e ruas do sistema urbano do Distrito Federal. Para o ano 2000, a situação é ilustrada na Figura 3 (novamente, as três linhas mais integradas são grafadas em traços mais espessos). A consideração do total das vias urbanas reforça o argumento apresentado, ao puxar o centro topológico do sistema para ainda mais longe do Plano Piloto, nas direções oeste e sudoeste. A integração média do sistema, constituído por 18.849 linhas axiais, é de 0,6181, enquanto a integração do Eixo Monumental (na parte que pertence à Esplanada dos Ministérios) é apenas 20\% maior do que este valor $(0,7419) .{ }^{14}$ Assim, a parte mais central do Plano Piloto sequer pertence ao núcleo integrador, se o considerarmos, seguindo Peponis et al. (1989), como constituído por 25\% das linhas mais acessíveis de todo o sistema: o Eixo Monumental situa-se apenas no piso das $40 \%$ linhas mais integradas.

Evidentemente, o núcleo integrador das cidades pode se deslocar no espaço ao longo do tempo. Em cidades costeiras, por exemplo, ele tenderá a se afastar da área da fundação inicial, à medida que a cidade cresce para o interior. Ou seja, o centro histórico, com o passar do tempo, pode tornar-se uma parte excêntrica da cidade. Isto foi o que se verificou, por exemplo, nos casos de Recife (Loureiro \& Amorim, 2000) e de Maceió
11 Poder-se-ia argumentar que esta acessibilidade topológica não corresponderia a uma acessibilidade "real", ou seja, em termos de distância métrica. Certamente haverá casos em que a distância métrica é uma poderosa variável explicativa. Neste trabalho, entretanto, atemo-nos a esta última, na esteira de um significativo acervo de pesquisa empírica que tem demonstrado a validade, em si, da dimensão topológica. Para mais informações, ver os Anais dos três simpósios internacionais de Sintaxe Espacial, constantes na bibliografia.

120 processamento dos mapas axiais foi feito por meio do Axman (Dalton, s.d.).

13 Para um apanhado mais detalhado deste processo, ver Mota et al., 2000. Os mapas foram preparados com base em Codeplan (1984a).

14 Para que o leitor tenha uma idéia da ordem de grandeza da medida de integracão, nos estudos de caso realizados em regiões específicas do Distrito Federal, a integração mais baixa (ou seja, o sistema menos permeável entre suas partes) foi obtida em parte da área central do Plano Piloto, considerados conjuntamente os Setores de Diversões Sul e Hoteleiro Sul - 0,81; e a integração mais alta foi obtida nas Superquadras 405/406 Norte - 3,34 (Holanda, 2002). Dada a estrutura extremamente segmentada do sistema urbano do DF, não admira que a sua integração média - 0,6181 - seja ainda menor do que a mínima encontrada numa região específica. 


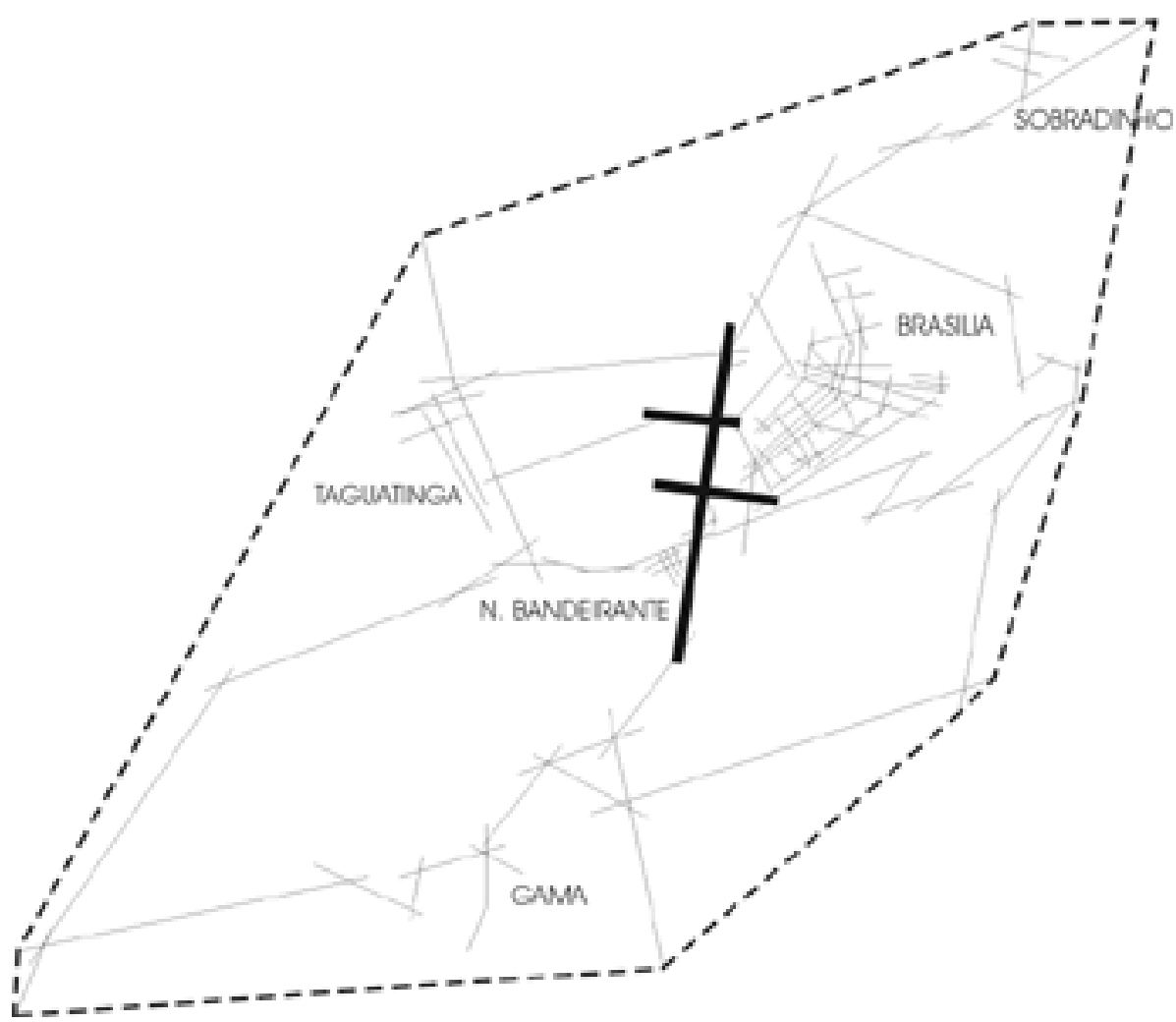

Figura 1 - Mapa axial das principais vias do Distrito Federal, Brasil, mostrando em traço mais espesso as três linhas mais integradas do sistema (1960).

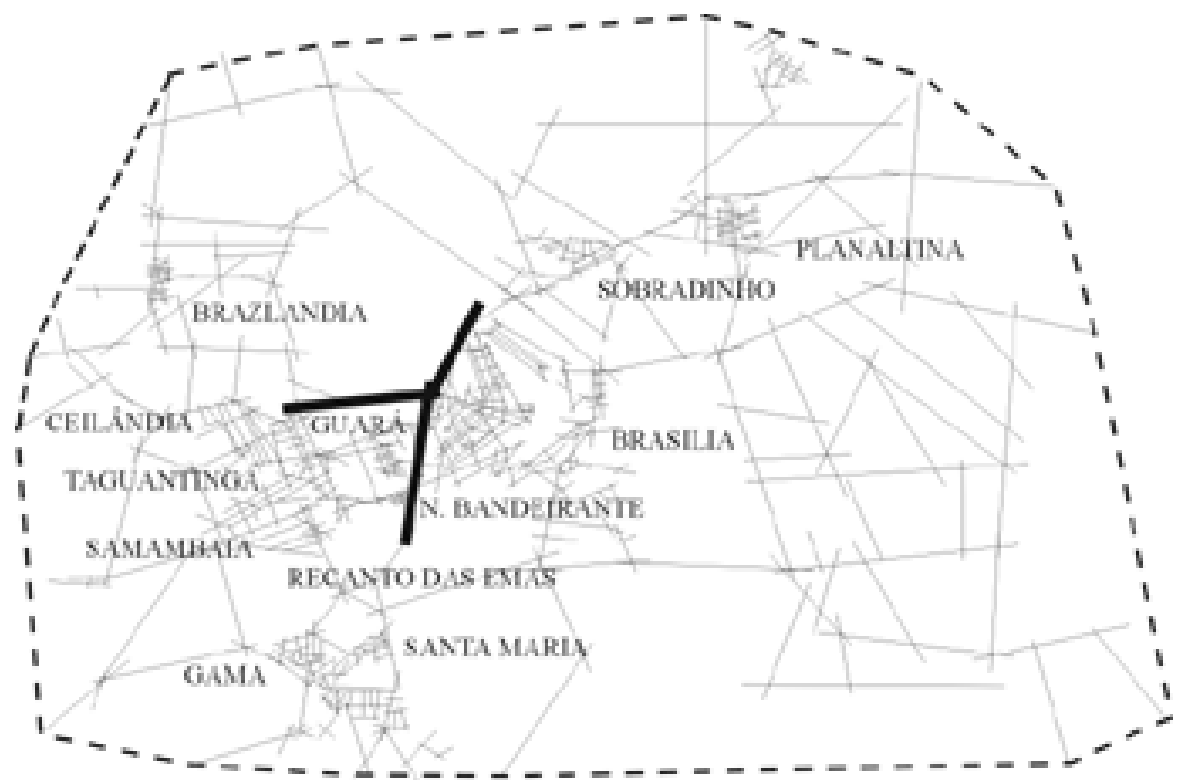

Figura 2 - Mapa axial das principais vias do Distrito Federal, Brasil, mostrando em traço mais espesso as três linhas mais integradas do sistema (1998). 


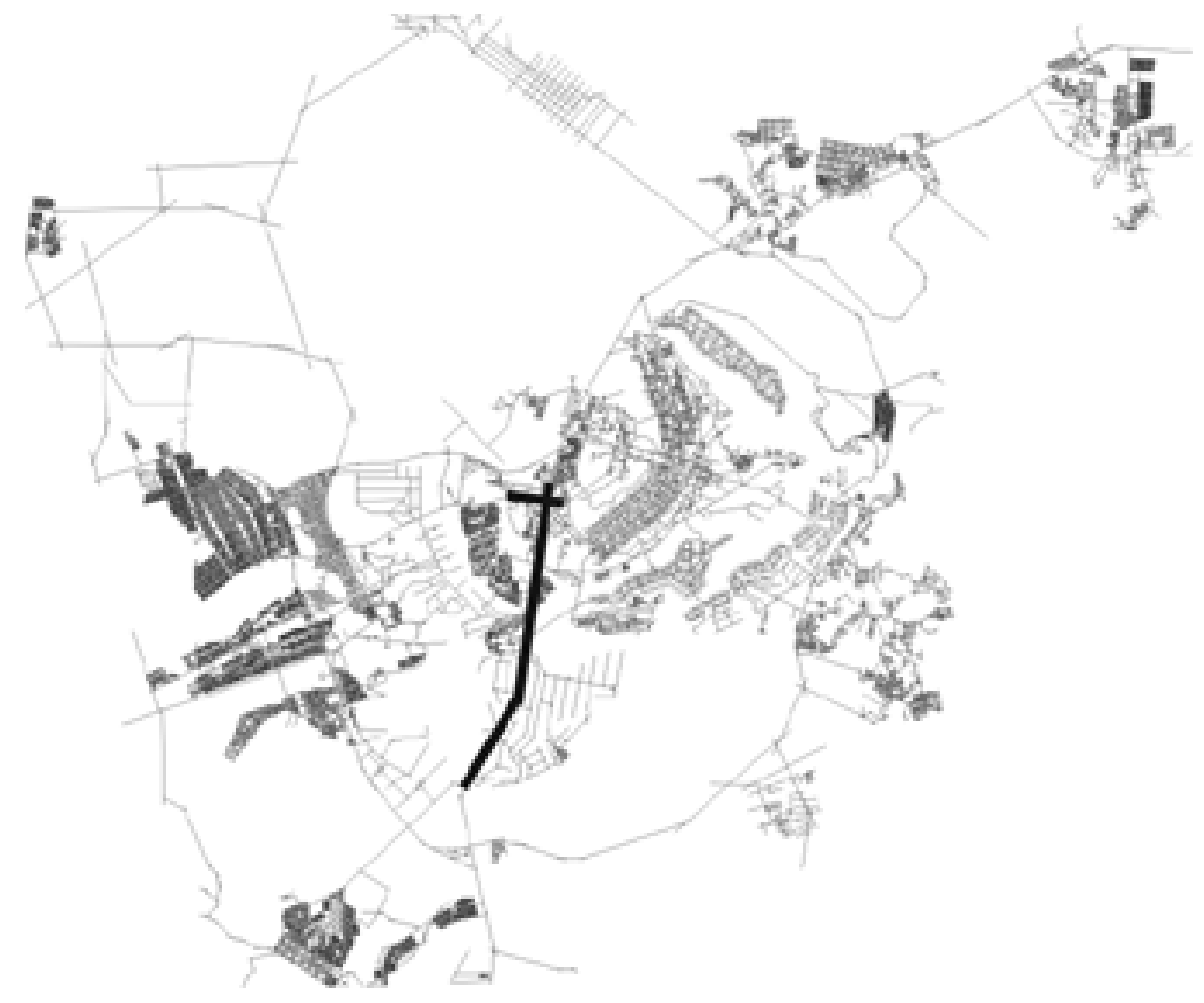

Figura 3 - Mapa de axialidade de todas as vias urbanas do Distrito Federal, mostrando em traço mais espesso as três linhas mais integradas do sistema (2000).

(Gusmão, 2001). A peculiaridade da capital federal brasileira reside, entretanto, no fato de o centro simbólico e/ou funcional - leia-se, o Plano Piloto -, nunca ter sido o centro morfológico. Veremos os problemas que isto implica. Antes, porém, voltemos nossa atenção para a segunda categoria configuracional tratada aqui: a compacidade.

\section{COMPACIDADE}

Recentemente, publicou-se interessante trabalho sobre a compacidade urbana, particularmente relativa a cidades do mundo "em desenvolvimento" (Jenks \& Burgess, 2000). Fatores como poluição, custos de transporte, densidades habitacionais, custos infra-estruturais etc. são analisados, mas não há uma exploração de variáveis que descrevam a própria forma da cidade no que diz respeito ao problema da compacidade, ou seja, não há exploração de variáveis propriamente morfológicas que possam informar mais precisamente um processo de desenho urbano. Neste trabalho, exploraremos duas alternativas: a primeira partindo das técnicas da sintaxe espacial e a segunda, de outras vertentes teóricas. Para distingui-las, chamaremos a primeira de compacidade axial, e a segunda de indice de dispersão, como se segue.

\section{COMPACIDADE AXIAL}

A medida de compacidade urbana aqui proposta baseia-se na divisão do número de linhas axiais por unidade de área. Para obtê-la, circunscrevemos o conjunto de linhas axiais 
15 Para efeito de comparação com esses outros casos, consideramos o total das linhas do sistema (ano de 2000), não apenas as vias arteriais, como tínhamos feito para os mapas históricos das décadas anteriores. Objetivando maior clareza, os números da Figura 7 resultam da divisão do número total de linhas do sistema, por 10 hectares de área do polígono convexo mínimo que as circunscreve, antes referido. a que foi reduzido o sistema urbano, com o menor polígono convexo possível, e calculamos a divisão entre o número de linhas do sistema e a área de tal polígono (esses polígonos também se encontram desenhados nas Figuras 1 e 2). Sistemas descontínuos, ou "nucleados" - como o de Brasília - apresentarão naturalmente menores índices de compacidade.

A variação da compacidade no Distrito Federal, ao longo do tempo, está ilustrada na Figura 4. Note-se como ela chega a cair na primeira década (anos 60), quando a cidade se torna mais rarefeita em razão da incorporação de núcleos bastante afastados - como a vernacular Planaltina (40 km do Plano Piloto), que sofreu então significativa expansão urbana. A compacidade cresce nas décadas subseqüentes, em razão do preenchimento de alguns espaços intersticiais. Entretanto, esta compacidade ainda está muito longe daquela encontrada em outras cidades brasileiras nas quais pudemos aplicar o mesmo procedimento metodológico (Figura 5). ${ }^{15}$ Apesar da expansão da área urbanizada ao longo destes mais de 40 anos, Brasília ainda apresenta, hoje, uma compacidade cerca de oito vezes menor do que a de um núcleo histórico como o de Belém.

\section{Medida de Compacidade}

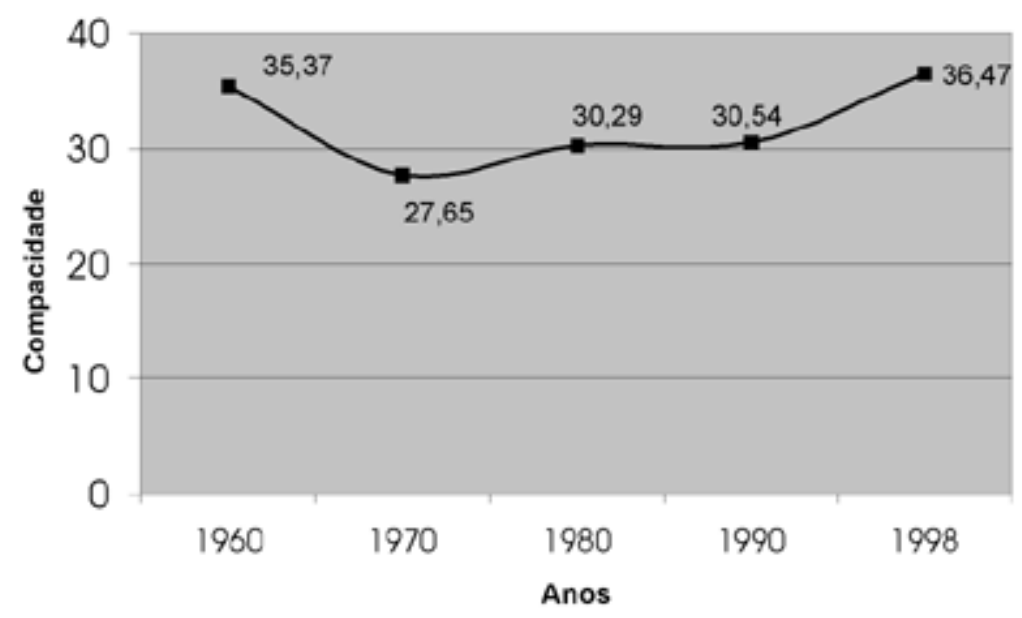

Figura 4 - Evolução da medida de compacidade no Distrito Federal, Brasil: 1960-1998.

\section{Compacidade comparativa}

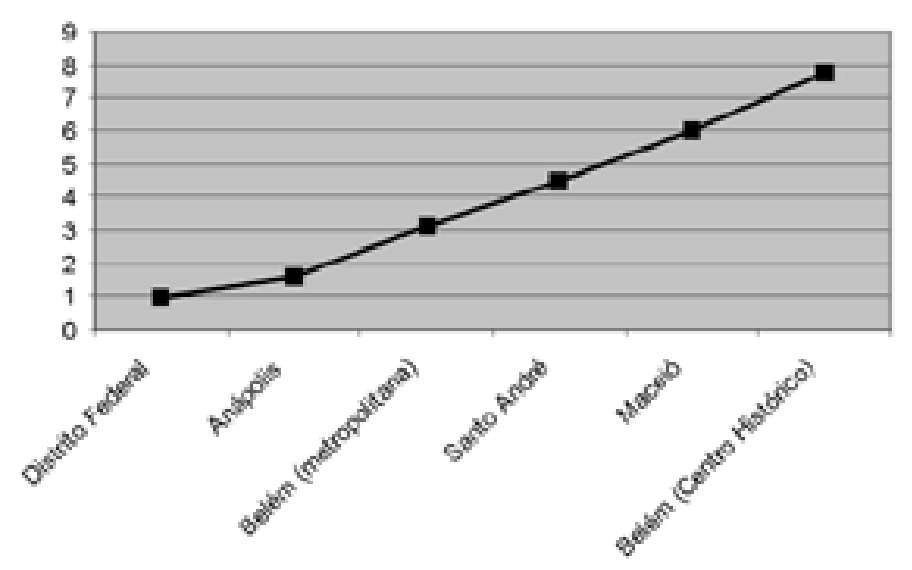

Figura 5 - Compacidade de uma amostra de áreas urbanas brasileiras. Note-se a alta compacidade de uma área colonial tradicional, como o Centro Histórico de Belém. 
A compacidade assim medida denuncia outros fatores mantidos constantes, a ocorrência de espaços não ocupados no tecido urbano, pelo que, no geral, temos um menor número de vias por hectare. $\mathrm{O}$ crescimento das distâncias médias entre destinos dentro da cidade obviamente aumenta, o que implica maiores custos socioeconômicos. É verdade que, variando-se outros fatores - como, por exemplo, o comprimento médio das vias haveríamos que utilizar algum procedimento de normalização, o que ainda não foi feito nesta etapa da pesquisa.

Se essa medida, como exposta aqui, tem qualidades, uma delas certamente é a sua simplicidade: uma vez disponível o mapa de axialidade de uma cidade, sua obtenção é praticamente imediata. Entretanto, ela tem óbvias limitações, como não levar em conta a questão das densidades urbanas, e sua distribuição no espaço. Veremos a seguir como, por meio de procedimentos um pouco mais laboriosos, este problema pode ser enfrentado. Chamaremos a medida assim obtida de indice de dispersão.

\section{ÍNDICE DE DISPERSÃO}

A segunda medida de compacidade explorada neste texto parte de Bertaud \& Malpezzi (1999). ${ }^{16}$ A idéia é simples: a forma da cidade analisada é comparada à forma circular de uma cidade hipotética de área equivalente. A fórmula para calcular o índice de dispersão, adaptada para efeito de maior clareza, é a seguinte:

$$
\rho=\frac{\sum_{i} \mathrm{~d}_{i} \mathrm{p}_{i}}{P C}
$$

onde o símbolo correspondente à letra grega "rho" - " $\rho$ " - é o índice de dispersão; "d" é a distância do centróide de cada setor urbano ao centro da cidade; "p" é a população de cada setor urbano; "P" é a população urbana total; e "C" é a distância média dos pontos de um círculo, de área equivalente à da cidade analisada, ao seu centro (que é igual a 2/3 de seu raio, valor obtido por meio de cálculo integral). ${ }^{17}$

Obtivemos assim, para Brasília, um índice de dispersão de 2,55, inferior apenas ao de uma das 35 cidades estudadas por Bertaud \& Malpezzi: Bombaim, de índice 3,08, e a mais compacta encontrada por esses autores, Shangai, com índice de 0,78 . Por curiosidade, vale assinalar que o Rio de Janeiro, com todos os acidentes geográficos que provocam uma forte descontinuidade do tecido urbano, atinge um índice de dispersão de $1,97 .{ }^{18}$ Bertaud \& Malpezzi sugeriram uma maneira de ilustrar a dispersão: os setores urbanos da cidade real são representados por prismas onde a base corresponde à área do setor, e a altura corresponde à sua respectiva densidade demográfica (Figura 6). Por outro lado, a Figura 7 ilustra a cidade circular teórica de área equivalente, onde a altura corresponde à densidade demográfica média do Distrito Federal (a escala desta altura é meramente convencional, mas é a mesma para as duas ilustraçōes). As duas Figuras ilustram tanto a dispersão quanto a localização das mais altas densidades demográficas na periferia.

Mas isto não é tudo. Para compreender melhor a problemática estrutura espacial da capital brasileira, é preciso considerar mais de perto as relações entre sua configuração, e a localização dos moradores e dos empregos, como se segue.
16 Os referidos autores alertam para o fato de que se trata ainda de versão altamente preliminar, e como tal deve ser considerada. Também, eles chamam esta medida de duas maneiras ao longo do texto: "índice de compacidade" e "índice de dispersão". Preferimos a segunda alternativa, pelo fato de que, em função da fórmula adotada, quanto mais dispersa cidade, mais alto será o valor obtido.

17 No nosso caso, os "setores urbanos" são constituídos pelas áreas urbanas das Regiões Administrativas do Distrito Federal. Para uma "sintonia fina" poderão ser utilizados os setores censitários, quando a informação estiver disponível. 0 "centro" urbano considerado foi o ponto de cruzamento do Eixo Monumental com o Eixo Rodoviário, no coração do Plano Piloto de Brasília, uma vez que nas suas proximidades concentra-se a grande maioria dos empregos do Distrito Federal.

18 Embora Bertaud \& Malpezzi falem em "região metropolitana", tudo indica que, pelos dados populacionais apresentados, eles consideraram, no caso do Rio de Janeiro, apenas a população do município. 


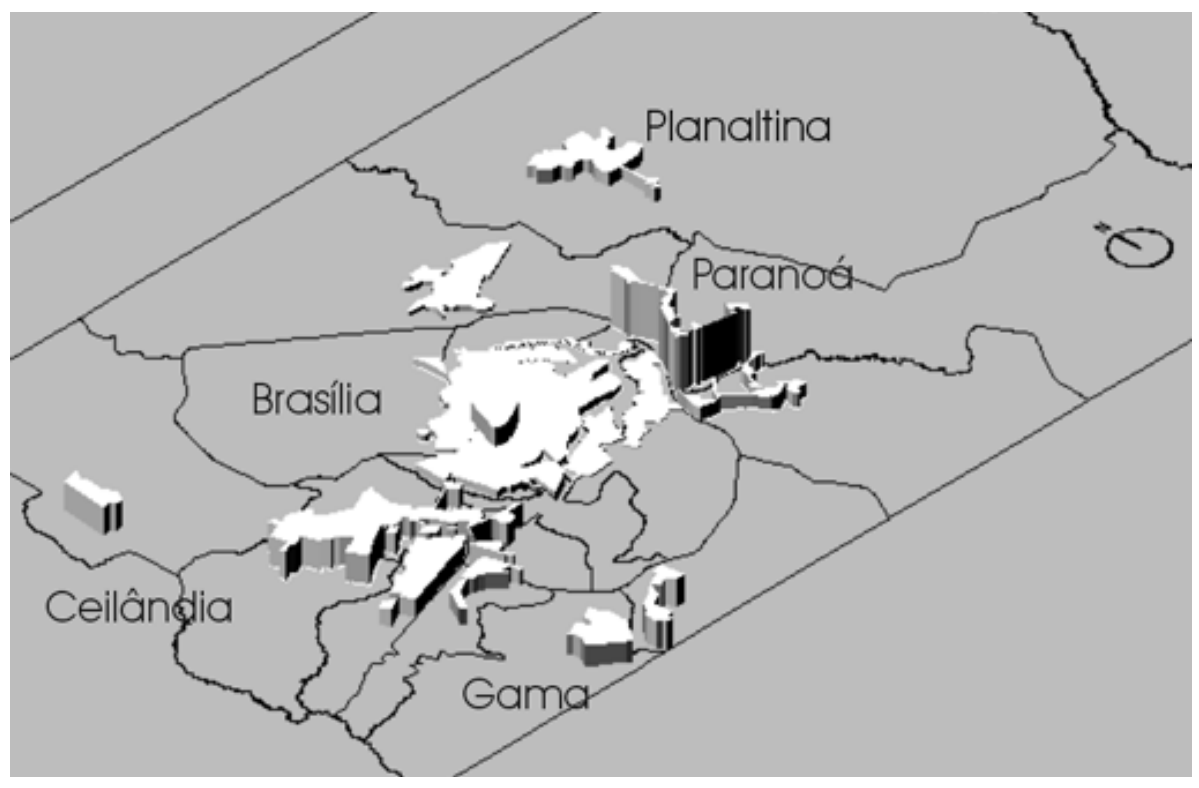

Figura 6 - Ilustração convencional de densidades de zonas urbanas do Distrito Federal, por Região Administrativa (a título de exemplo, foram nomeadas algumas zonas urbanas).

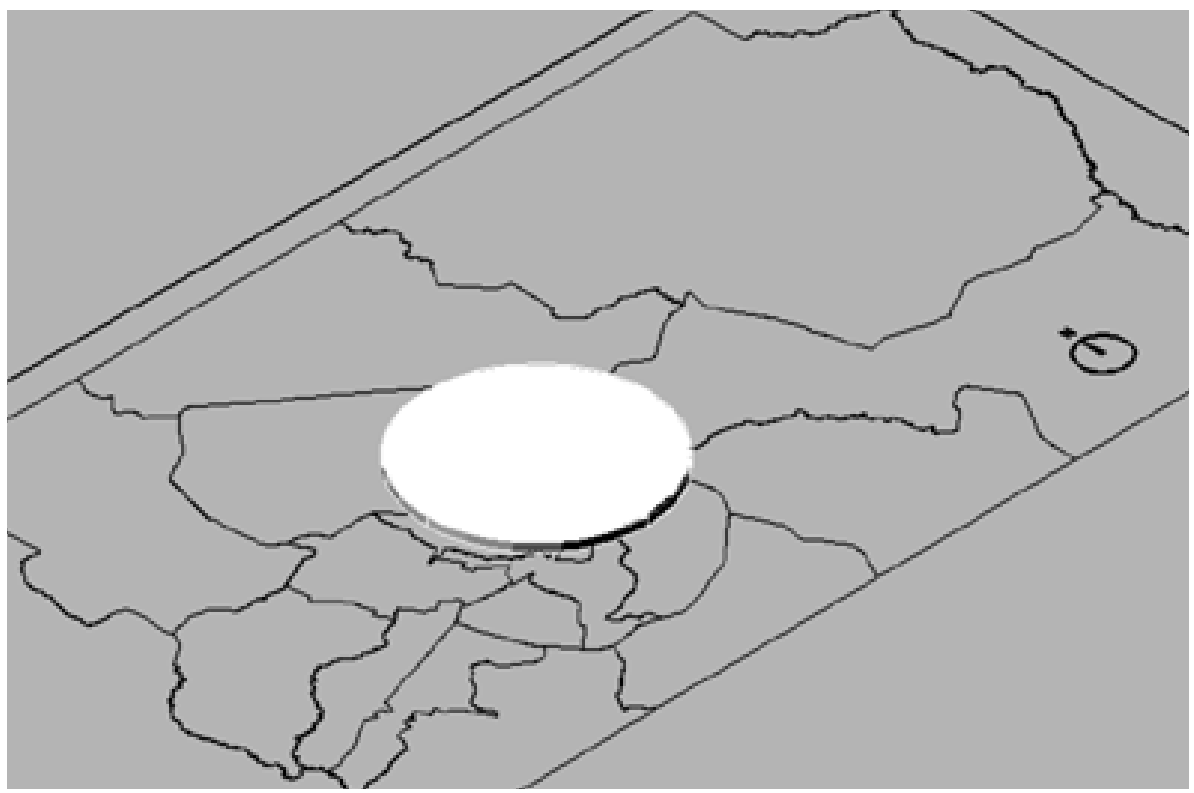

Figura 7 - Ilustração convencional da densidade de uma cidade hipotética cilíndrica, com a densidade média e a mesma superfície urbana do total das zonas urbanas do Distrito Federal.

\section{MORADORES, EMPREGOS E INTEGRAÇÃO}

O Distrito Federal está hoje dividido em 19 Regiōes Administrativas ("RAs", daqui em diante), que constituirão a referência geográfica básica na análise que se segue (o Plano Piloto situa-se na RA1, denominada "Brasília" - cuja área praticamente coincide com a área do projeto original). A Tabela 1 indica, por RA, os valores de integração, moradores e empregos. O forte desequilíbrio entre estas três variáveis pode ser caracterizado 
quantitativamente, por meio de correlaçôes simples ${ }^{19}$ entre os seus valores. Para tanto, tivemos que calcular uma medida de integração "regional". Vimos como, a cada linha do mapa de axialidade, corresponde uma medida de integração; para chegarmos a um número correspondente à região, utilizamos a média dos valores das três linhas mais integradas que se localizam completamente dentro das fronteiras administrativas da região considerada. A Figura 8 ilustra graficamente a correlação obtida entre estes valores. ${ }^{20}$

Tabela 1 - Integração, empregos e habitantes, por Região Administrativa - DF

\begin{tabular}{lrrr}
\hline RAs & Integração & Empregos & Habitantes \\
\hline RA I Brasília & 0,9306 & 555.369 & 198.422 \\
RA X Guará & 0,9714 & 72.473 & 115.385 \\
RA III Taguatinga & 0,8898 & 31.481 & 243.575 \\
RA IX Ceilândia & 0,6961 & 24.000 & 344.039 \\
RA XVI Lago Sul & 0,8049 & 11.228 & 28.137 \\
RA V Sobradinho & 0,8494 & 7.431 & 128.789 \\
RA XI Cruzeiro & 0,9315 & 6.441 & 63.883 \\
RA II Gama & 0,8745 & 5.773 & 130.580 \\
RA VIII Núcleo Bandeirante & 0,9660 & 5.377 & 36.472 \\
RA XII Samambaia & 0,8919 & 3.335 & 164.319 \\
RA VI Planaltina & 0,6343 & 3.040 & 147.114 \\
RA XIII Santa Maria & 0,8398 & 1.760 & 98.679 \\
RA XV Recanto das Emas & 0,8627 & 1.669 & 93.287 \\
RA XVIII Lago Norte & 0,7816 & 1.321 & 29.505 \\
RA IV Brazlândia & 0,6840 & 1.255 & 52.698 \\
RA VII Paranoá & 0,6477 & 626 & 54.902 \\
RA XIV São Sebastião & 0,5917 & 574 & 64.322 \\
RA XVII Riacho Fundo & 0,8619 & 432 & 41.404 \\
RA XIX Candangolândia & 0,9075 & 375 & 15.634 \\
\hline Totais & & 733.960 & 2.051 .146 \\
\hline correlação integração/empregos & & & 0,27 \\
correlação integração/habitantes & & & $-0,03$ \\
correlação empregos/habitantes & & & 0,31 \\
\hline Fonte Pesauin DIMU & &
\end{tabular}

Fonte: Pesquisa DIMPU, MTE (1999), IBGE (2000).

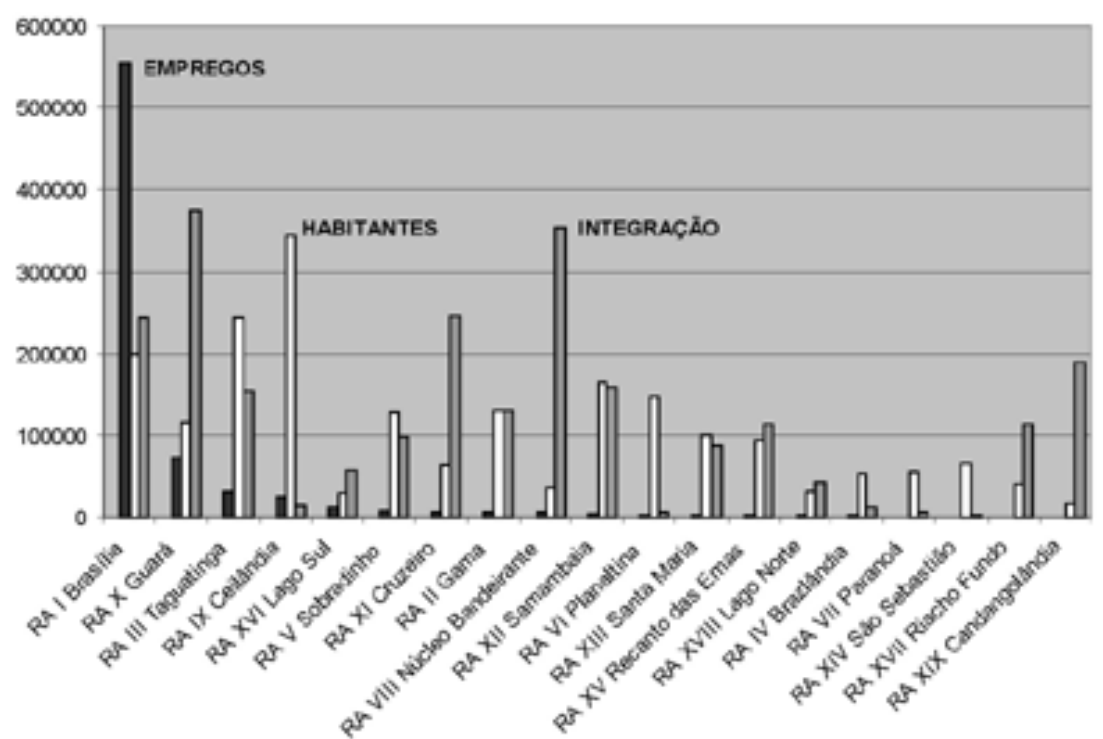

Figura 8 - Moradores, empregos e integração, nas Regiões Administrativas do Distrito Federal, Brasil.
19 A medida estatística de correlação simples indica a maneira pela qual duas séries de valores estão relacionadas. Se as duas séries variam no mesmo sentido (enquanto os valores de uma crescem, os de outra também crescem), a correlação é positiva, podendo a medida chegar ao máximo de +1 . Se as duas séries variam em sentido inverso (enquanto os valores de uma crescem, os da outra decrescem), a correlação é negativa, podendo a medida chegar ao mínimo de -1 .

20 Pode-se notar na Figura 8 que os valores de integração não coincidem com a escala tradicional de valores de integração como encontrados na literatura (em torno de 1 a 2). A questão é que, por razões de ilustração, estes valores foram "normalizados" de maneira a facilitar visualmente a comparação com o número de habitantes e empregos, revelando assim a baixa correlação obtida. Para tanto, os valores de integração foram submetidos a uma potência de 10, e em seguida multiplicados por 500.000 . Entretanto, os valores originais foram mantidos para o cálculo das correlações comentadas no texto, e indicadas na Tabela 1. 
21 E preciso notar que a fonte utilizada aqui é a base de dados do Ministério do Trabalho e Emprego. Uma análise cuidadosa destes dados sugere que há superestimação da localização de empregos na cidade central: contempla-se aqui apenas os empregos formais, que se concentram obviamente na Região Administrativa I (Brasília). Entretanto, acreditamos que estes dados ainda constituem uma boa indicação da realidade presente.

22 Dados publicados pelo Jornal de Brasília, em 15/05/2001, com base em informações de Departamentos Municipais de Transportes Urbanos. Infelizmente, ainda não dispomos, por nossa metodologia, de dados de compacidade de $\mathrm{Cu}$ ritiba ou Vitória, para fazermos uma análise mais completa.

23 Estudos ainda em andamento por nosso grupo de pesquisa, além de trabaIhos já anteriormente citados (Rigatti, 1997; Loureiro \& Amorim, 2000; Trigueiro et al., 2001).
Os baixos valores de correlação da Tabela 1 constituem indicadores de três importantes aspectos relacionados:

a) a disparidade entre a localização de empregos e de moradia é captada pela correlação de 0,31 , pela qual a grande concentração de empregos formais na Região de Brasília $(76 \%)$ corresponde a apenas um relativamente pequeno número de habitantes (9,7\% do total do Distrito Federal), enquanto a região mais populosa (Ceilândia) tem um número desprezível de empregos formais; ${ }^{21}$

b) o grande número de habitantes em partes altamente segregadas do sistema é captado pela correlação ligeiramente negativa de $-0,03$, indicando que as grandes massas populacionais estão nas partes mais segregadas do sistema;

c) a excentricidade da grande maioria dos empregos (no Plano Piloto, relativamente segregado, como vimos) é captada pela baixa correlação de 0,27 , entre empregos e integração.

Por enquanto ainda não temos dados quantitativos semelhantes que permitam uma análise comparativa com outras cidades brasileiras, mas os resultados acima parecem muito típicos da capital. Em outras cidades, certamente algumas áreas são mais privilegiadas quanto à localização de empregos, e a maioria esmagadora da população vive longe do trabalho. Entretanto, o fato de os próprios empregos serem excêntricos, e a sua concentração espacial corresponder a um número tão relativamente pequeno de habitantes, parece ser típico de Brasília.

Mas, afinal, por que Brasília teria mesmo de ser central? Parece claro que a forte contradição entre a localização de empregos e de habitaçôes implica maiores distâncias entre casa e trabalho, com custos sociais mais elevados. Ainda precisamos de estatísticas mais ilustrativas, mas estudos disponíveis sobre transporte público no Brasil já nos dizem algo importante sobre isto. Em Brasília, o IPK (Índice de Passageiro por Quilômetro de linhas de ônibus, uma maneira clássica de se medir a eficiência do transporte coletivo) é de 1,1. No Rio de Janeiro, cidade bem mais compacta do que Brasília, como vimos, ele é 47\% mais elevado do que em Brasília, e em relação à Curitiba ele é 131\% mais elevado. Há também uma correlação clara entre estes índices e o preço das tarifas: Brasília é campeã, com as mais elevadas tarifas do Brasil ( $\mathrm{R} \$ 1,50), 36 \%$ mais elevadas do que em Vitória $(\mathrm{R} \$ 1,10)$, que vem em segundo lugar, e $50 \%$ mais altas do que em Curitiba, que vem em terceiro. ${ }^{22}$ Devemos também ressaltar que, apesar de termos aqui o mais alto índice de motorização do País (1,8 pessoas por veículo), 52,7\% das viagens diárias, para todos os motivos, ainda são feitas por transporte coletivo, sendo $44,3 \%$ feitas por automóvel (Codeplan, 1991).

Em outras palavras, uma importante peculiaridade de Brasília em face de várias outras cidades brasileiras nas quais já foi possível aplicar alguns destes procedimentos metodológicos é que, em Brasília, centro morfológico e centro funcional não coincidem. Em cidades como Natal, Recife, Porto Alegre, Maceió ou Belém, ${ }^{23}$ por exemplo, estudos de evolução urbana têm mostrado que, consistentemente, o centro morfológico vai se deslocando, ao longo do tempo, junto com o centro funcional da cidade, mantendo-se sempre uma coincidência quase rigorosa entre eles. Os dados de que dispomos até aqui parecem convincentemente indicar que os fatores configuracionais estudados neste texto - excentricidade de empregos e serviços e baixa compacidade - são fortemente responsáveis por um mal desempenho de Brasília em aspectos que atingem em cheio principalmente a população de menor poder aquisitivo. 


\section{UMA ESPECULAÇÃO}

Preocupações quanto aos índices comentados acima já estiveram presentes em propostas de desenho urbano para o Distrito Federal. O PEOT - Plano Estrutural de Organização Territorial (Codeplan, 1977), por exemplo, já na década de 1970, propunha uma estrutura urbana onde o uso do solo estivesse concentrado ao longo de corredores de transporte de massa. A nova cidade de Águas Claras está sendo implantada em uma das áreas de dinamização propostas pelo PEOT, e seu projeto implicava significativa transferência de empregos da Região de Brasília para a Região de Taguatinga. Lamentavelmente, tal intenção não vem se concretizando. No que se segue, verificamos como o projeto de Águas Claras, assim como outras medidas de desenho urbano, que poderiam ser eventualmente adotadas, interfeririam nos indicadores comentados acima. Por outro lado, isto funciona como teste destes indicadores, pois revela o grau em que eles são sensíveis a tais transformações.

A Tabela 2 ilustra um cenário hipotético, em que algumas modificações são feitas em face da situação atual: a) reduzem-se os empregos em Brasília e amplia-se a sua população; b) ampliam-se os empregos e a população de Taguatinga, como resultado da implantação de Águas Claras. Esta especulação considera o número de empregos e de habitantes originalmente previstos para Águas Claras (pensava-se na transferência de alguns órgãos do governo local para a nova cidade, e em altas densidades habitacionais). No caso da Região de Brasília, foram considerados novos contingentes populacionais que poderiam ser absorvidos no futuro Setor Noroeste, assim como um incremento de moradores ao longo da Avenida W-3, por meio de modificação de usos e gabaritos. ${ }^{24}$ A nova cidade de Águas Claras, o Setor Noroeste, e a Av. W-3 estão indicados na Figura 9. Os novos valores de empregos e habitantes, assim como os novos valores das correlações obtidas estão registrados na Tabela 2.

Tabela 2 - Integração, empregos e população - correlações num cenário hipotético

\begin{tabular}{lrrrr}
\hline Região Administrativa & Hoje & \multicolumn{3}{c}{ Cenário hipotético } \\
\cline { 2 - 5 } & População & Empregos & População & Empregos \\
\hline RA I Brasília & 198.422 & 555.369 & 600.000 & 485.000 \\
RA III Taguatinga & 243.575 & 31.481 & 363.575 & 101.481 \\
\hline Correlação integração/empregos & 0,27 & & 0,29 & \\
Correlação integração/habitantes & $-0,03$ & & 0,15 & \\
Correlação empregos/habitantes & 0,31 & & 0,84 & \\
\hline
\end{tabular}

Note-se que a correlação que mais melhorou foi aquela entre empregos e habitantes, o que indica uma mais eqüitativa distribuição dessas duas categorias na cidade. As transformações de desenho urbano especuladas também melhoram significativamente a correlação entre integração e habitantes, na medida em que aumentam o contingente populacional na área central - que ainda é, apesar de sua excentricidade, relativamente integrada. O menor impacto se dá na correlação entre empregos e integração, o que é compreensível: seria preciso aumentar muito mais o número de empregos nas demais cidades do Distrito Federal para que esta correlação sofresse impacto mais forte. Em síntese, uma cidade assim mais equilibrada muito ganharia em urbanidade, se por isso entendemos, entre outras coisas, menores custos sociais de deslocamento, maior acessibilidade aos equipamentos públicos, mais fácil utilização do espaço urbano como recurso cultural. ${ }^{25}$
24 Esta especulação de transformação da Avenida W-3 está relatada em Silva et al., 2001.
25 Em Holanda (1999; 2002) encontra-se uma discussão mais longa sobre 0 conceito de urbanidade. A idéia de espaço como recurso cultural está desenvolvido em Peponis (1992). 


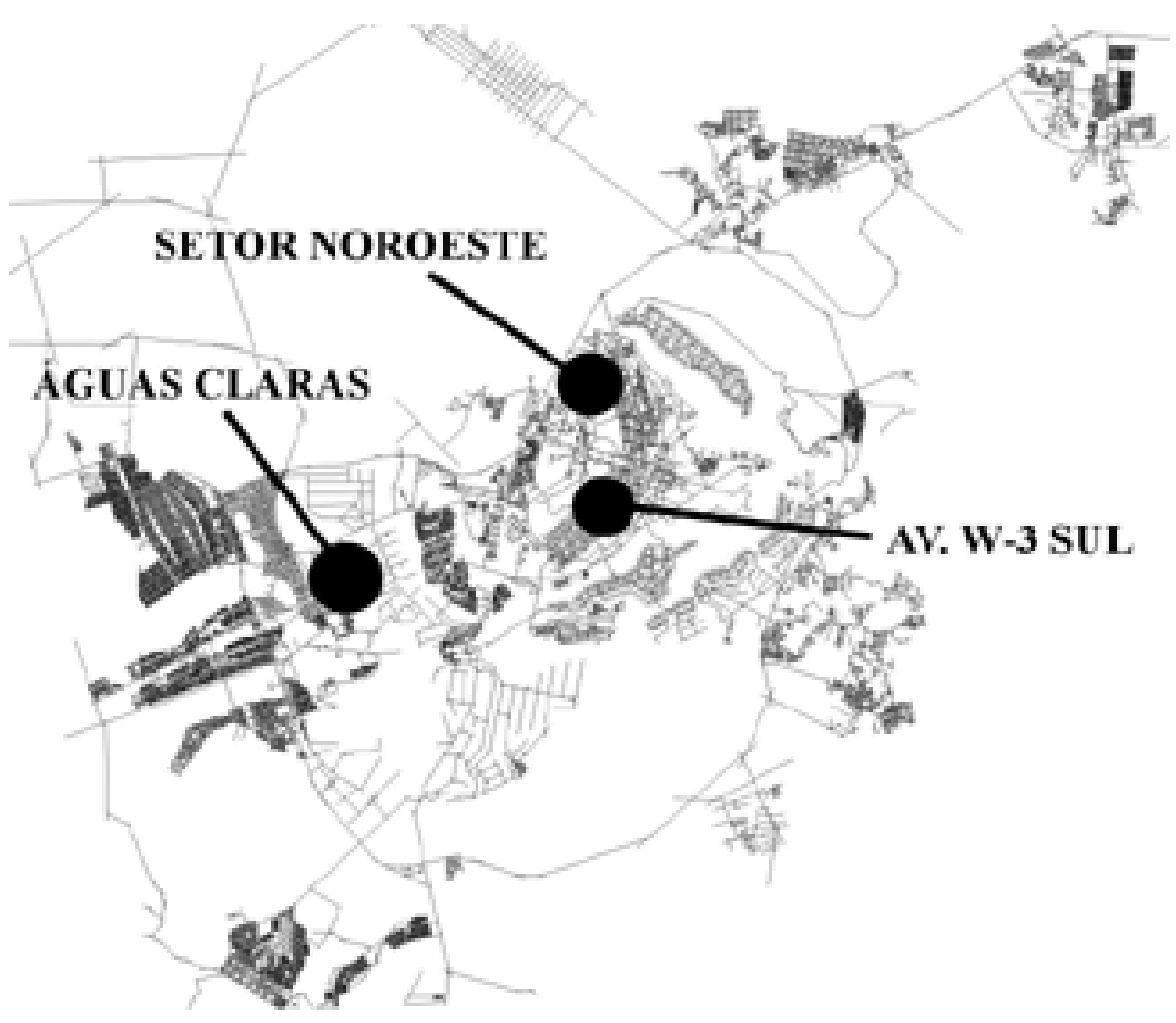

Figura 9 - Mapa axial do DF, mostrando a localização de Águas Claras, Setor Noroeste e Av. W-3 Sul.

Finalmente, ilustramos a seguir como estes procedimentos metodológicos permitem simular o impacto de uma obra como a Ponte JK - a terceira ponte ora em construção sobre o lago Paranoá. O interesse deste exemplo reside no fato de que posições conceituais diferentes sobre a organização territorial da cidade mais uma vez entraram em confronto, recolocando-se a dicotomia integração/segregação do Plano Piloto em face da cidade maior.

\section{UMA CONTROVÉRSIA EMBLEMÁTICA}

Controvérsias sobre o desenvolvimento espacial da cidade revelam freqüentemente os diferentes pontos de vista ideológicos sobre sua configuração. Isto é exatamente o que ocorreu com o debate sobre a construção da terceira ponte sobre o lago, que ligará o extremo leste da Esplanada dos Ministérios, por sobre o lago Paranoá, às áreas habitacionais na margem oposta (Figura 10). A construção já se encontra em curso, e havia várias alternativas de conexão da ponte com a parte monumental da cidade. Ela poderia a) conectar-se com uma via periférica e/ou com ruas alternativas que contornam a Esplanada, ou b) conectar-se diretamente com a extremidade leste do Eixo Monumental. A primeira alternativa foi apoiada por aqueles que defendem "o caráter original do lugar", pelo que a Esplanada deve ser mantida, tanto quanto possível, como um pedaço isolado (e deserto, poderíamos acrescentar) da cidade. A segunda alternativa foi defendida pelos construtores, que propunham uma ligação mais direta com o centro da cidade. 


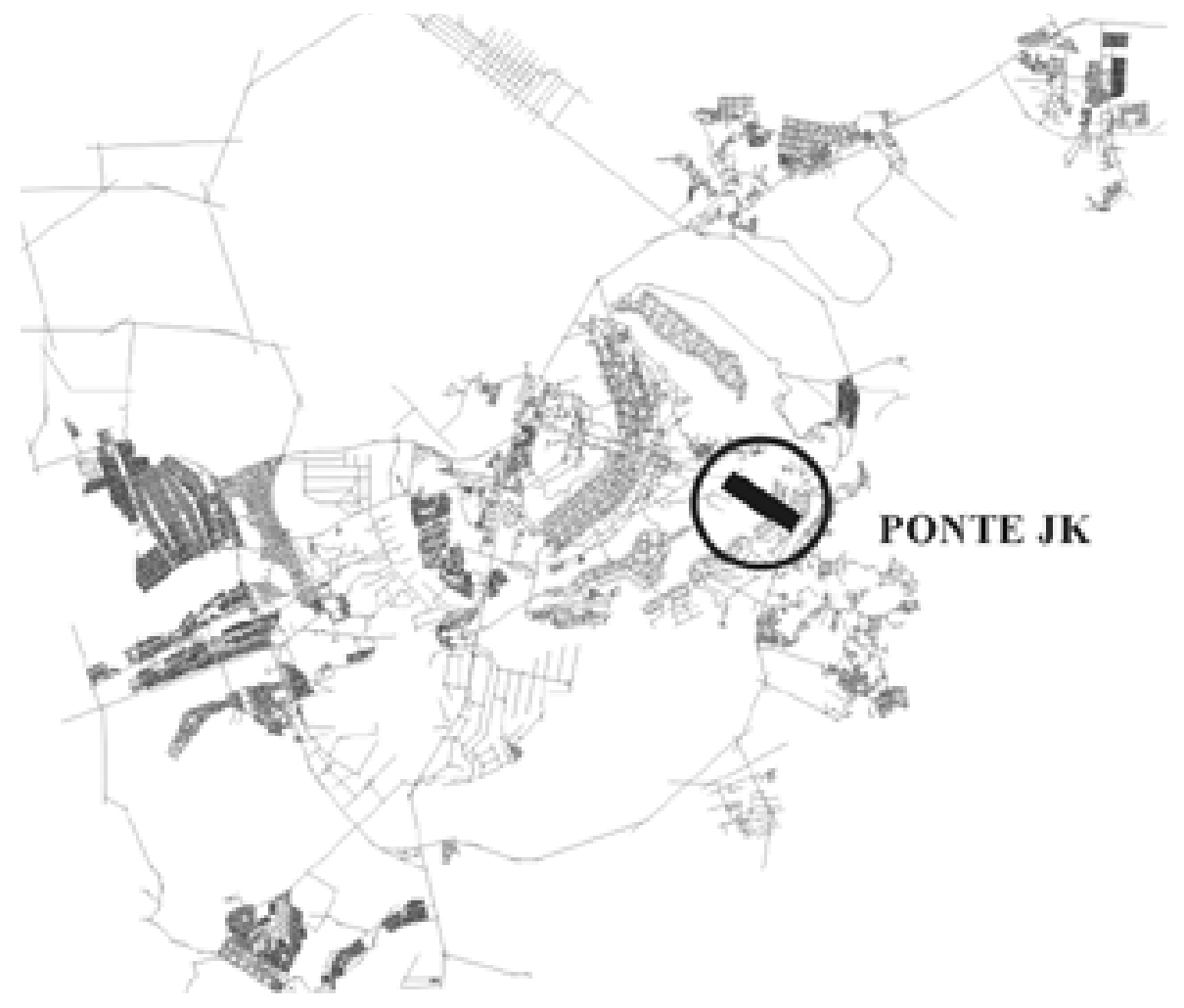

Figura 10 - Localização da Ponte JK, sobre o lago Paranoá.

A controvérsia está longe de constituir qualquer novidade, pois é parte do velho debate que de vez em quando volta à superfície: a necessidade ou não de se manter a cidade - ou pelo menos sua parte monumental - incólume à vida secular. Podemos lembrar aqui o apelo de Lúcio Costa pela manutenção da "fisionomia" da cidade, e dos esforços recorrentes para somente permitir a urbanização crescente longe do coração administrativo federal (ver acima). A análise configuracional revela que os "isolacionistas" percebem intuitivamente a maior integração que se obteria na Esplanada com uma ligação mais intensa com o seu entorno: uma simulação, incluindo a terceira ponte, indica um crescimento de (apenas) 5,2\% na medida de integração do principal eixo que atravessa o lugar, a qual passaria de 0,7418 para 0,7808 . Por outro lado, revela o enorme preconceito quanto a uma maior "secularização" deste espaço monumental, porque, ao fim e ao cabo, é disso que se trata. De fato, como vimos, o impacto configuracional é realmente muito pequeno para tal reação, particularmente se calibrarmos a integração com a (baixa) densidade residencial do outro lado do lago, algo que pretendemos realizar em futuro próximo.

De qualquer maneira, uma maior integração certamente significaria um acesso mais fácil para a Esplanada, com todas as implicações - éticas e estéticas - que adviriam disto. Eticamente, a estratégia de isolar fisicamente a sede do poder resultaria enfraquecida - uma estratégia, aliás, adotada historicamente por sociedades autoritárias (Holanda, 1999). Esteticamente, mais pessoas desfrutariam melhor da inegável beleza do lugar na sua vida cotidiana, pois a Esplanada deixaria de ser apenas o ponto final de viagens dos funcionários públicos (e/ou dos raros visitantes), e se tornaria também um notável evento espacial ao longo de viagens rotineiras cuja origem e destino estariam fora dela. Em outras palavras, mais pessoas também desfrutariam o lugar de dentro e 
instrumentalmente, em vez de apenas de fora e simbolicamente - analogamente ao já observado, ele ganharia em urbanidade.

\section{CONCLUSÃO}

Brasília, quando analisada no nível global da metrópole, repete modelos de subúrbios e modos de vida conhecidos noutras cidades e noutras épocas, porém aqui este processo foi institucionalizado pelo próprio Estado, e não pelas "forças de mercado". Noutros casos, e via de regra, as elites dominantes criam a segregação por meio dos vazios urbanos mantidos como reserva de valor. Aqui, grande parte da terra sendo estatal - pelo menos inicialmente -, a segregação se deu por decisão política, e a partir de órgãos do Estado, pelo que contingentes de menor poder aquisitivo eram localizados a dezenas de quilômetros do Plano Piloto.

É irônico que assim seja. Mas foi-se o tempo em que se acreditava que a propriedade estatal da terra garantiria uma estrutura espacial mais democrática. A análise de Brasília desmitifica isso, revelando que o Estado e o interesse público só coincidem em circunstâncias políticas específicas. O Brasil constitui um destes países nos quais o Estado, ainda mais fortemente do que sói acontecer, é capturado pelas classes dominantes, para a defesa de seus próprios interesses. Assim não deveria constituir surpresa o fato de que a organização do território do Distrito Federal - a sede do governo federal - constitua uma estrutura espacial tão fortemente segregadora.

Esse modelo não é "ilógico" nem "irracional". Opções de desenho urbano, em qualquer tempo e lugar, implementam determinados valores, e não outros, escolhem determinadas prioridades, e não outras. Alternativas de desenho podem implicar diferentes ênfases em aspectos sociais, ou econômicos, ou simbólicos, ou ambientais etc. Argumentamos que os custos socioeconômicos de Brasília são muito elevados. Pelo menos para alguns defensores do status quo, esses custos não são ignorados, mas são defendidos em nome de uma determinada "fisionomia" urbana, como vimos: um preço que é preciso pagar pela dimensão simbólica da Capital Federal. Será mesmo? Ou o que testemunhamos aqui é uma determinada maneira de tratar a dimensão simbólica, entre outras que a história nos ensina?

Noutro trabalho, Brasília foi caracterizada como um tipo historicamente recorrente: um espaço de exceção (Holanda, 2002). Ou seja, um espaço especializado para funções sociais super-estruturais, e fisicamente isolado. A crítica de Brasília, num nível mais profundo, é a crítica deste tipo histórico, que tem um certo desempenho, que trata os vários aspectos do espaço urbano de determinada maneira. Para que a discussão sobre a cidade não constitua um "diálogo de surdos", é preciso explicitar suas várias dimensões de desem-

Frederico de Holanda, arquiteto, é professor do Programa de Pós-Graduação em Arquitetura e Urbanismo da Universidade de Brasília. E-mail: fredhol@ unb.br penho, assim como discutir maneiras alternativas de tratá-las. Não consideramos os vários problemas identificados neste texto como um preço necessário a pagar pela dimensão simbólica da Capital. Essa dimensão simbólica poderia ser diferentemente estruturada, como foi brevemente sugerido acima. Mas o aprofundamento do assunto já é tema para uma outra oportunidade. 


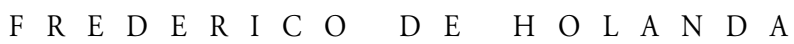

\section{REFERÊNCIAS BIBLIOGRÁFICAS}

BERTAUD, A.; MALPEZZI, S. The spatial distribution of population in 35 world cities: the role of markets, planning, and topography, 1999. (Mimeo.)

CODEPLAN. Plano estrutural de organização territorial do DF (PEOT). Brasília: Convênio Seplan/GDF, 1977.

. Atlas do Distrito Federal. Brasília: Codeplan, 1984a. v.3.

. Caracterização do território e da população do Distrito Federal. Brasília: Codeplan, 1984b. 9 v.

. Pesquisa domiciliar transporte. Brasília: Codeplan, 1991.

COSTA, L. Brasilia revisitada. Brasília: Diário Oficial do Distrito Federal - Decreto No 10.829 de 14 de outubro de 1987.

Lúcio Costa: registro de uma vivência. São Paulo: Empresa das Artes, 1995.

DALTON, N. Axman. London: University College, s.d.

DER/DF. Estatística de tráfego. Brasília: DER/DF, 1997.

FACULDADE DE ARQUITETURA E URBANISMO DA UNIVERSIDADE DE BRASÍLIA. SPACE SYNTAX II INTERNATIONAL SYMPOSIUM. 1999. Brasília. Proceedings. Brasília: Faculdade de Arquitetura e Urbanismo da Universidade de Brasília, 1999.

GOROVITZ, M. Brasília, uma questão de escala. São Paulo: Projeto Editores, 1985.

GUSMÃO, C. As faces da arquitetura na cidade contemporânea - o caso de Maceió - AL. Brasília, 2001. Dissertação (Mestrado) - Universidade de Brasília.

HILLIER, B.; HANSON, J. The social logic of space. Cambridge: Cambridge University Press, 1984.

HOLANDA, F. de. "Class footprints in the landscape". SPACE SYNTAX - II INTERNATIONAL SYMPOSIUM. 1999. Brasília. Proceedings. Brasília: Faculdade de Arquitetura e Urbanismo, Universidade de Brasília, 1999, p. 6.1 - 6.9.

. O espaço de exceção. Brasília: Editora Universidade de Brasília, 2002.

IBGE. Sinopse preliminar do Censo Demográfico de 2000. Página da Internet: www. ibge.gov.br.

JENKS, M.; BURGESS, R. Compact cities: sustainable urban forms for developing countries. London: Spon Press, 2000.

LOUREIRO, C.; AMORIM, L. O mascate, o bispo, o juiz e os outros: sobre a gênese morfológica do Recife. Revista Brasileira de Estudos Urbanos e Regionais, Recife, n.3, p.19-38, nov. 2000.

MACHADO, L. Z.; MAGALHĀES, T. Q. Imagens do espaço: imagens de vida. In: PAVIANI, A. (Org.) Brasilia, ideologia e realidade. São Paulo: Projeto Editores, 1985.

MINISTÉRIO DO TRABALHO E EMPREGO. Cadastro de estabelecimentos empregadores - Base estatística e cadastral. Brasília: MTE, 1999. (CD-Rom.)

MOTA, A. M. P.; HOLANDA, F. de; SOARES, L. R. S. de B.; GARCIA, P. M. Brasília nasceu excêntrica?. VI SEMINÁRIO DE HISTÓRIA DA CIDADE E DO URBANISMO. 2000. Natal. Anais... Natal: Programa de Pós-Graduação em Arquitetura e Urbanismo, UFRGN, 2000. (CD-Rom.)

PEPONIS, J. et al. The spatial core of urban culture. Ekistics, v.56, n.334/5, p.43-55, jan.-abril 1989.

Espaço, cultura e desenho urbano. Arquitetura e Urbanismo, ano 8, n.41, p.78-83, abr.-maio 1992. 
PEPONIS, J.; WINEMAN, J.; BAFNA, S. SPACE SYNTAX III INTERNATIONAL SYMPOSIUM. 2001. Ann Arbor. Proceedings. Ann Arbor: A. Alfred Taubman College of Architecture and Urban Planning, 2001.

RIGATTI, D. Do espaço projetado ao espaço vivido: modelos de morfologia urbana no Conjunto Rubem Berta. São Paulo, 1997. Tese (Doutorado) - Faculdade de Arquitetura e Urbanismo da Universidade de São Paulo.

SILVA, A. S. da; HOLANDA, F. de; BRITTO, L. M. B. L. de; MOURA, L. H. F.; FERREIRA, R. B. W-3, Brasília: A luta do dragão do consumo contra a santa sociabilidade. IX ENCONTRO NACIONAL DA ANPUR. Rio de Janeiro. 2001. Anais... Rio de Janeiro: Ippur/UFRJ, 2001. p.624-635.

SPACE SYNTAX LABORATORY. SPACE SYNTAX FIRST INTERNATIONAL SYMPOSIUM. London: Space Syntax Laboratory, 1997.

TRIGUEIRO, E. et al. Disneyfication now? Assessing spatial correlates for heritage preservation in Natal (Brazil). SPACE SYNTAX III INTERNATIONAL SYMPOSIUM. Ann Arbor. 2001. Proceedings. Ann Arbor: A. Alfred Taubman College of Architecture and Urban Planning, 2001. p.66.1-66.7.

A B S T R A C T This paper explores quantitative analytic procedures in order to characterise three types of morphological attributes of the Brazilian Capital. First, the Pilot Plan is not central concerning the larger urban system in which it is situated and, contradicting principles put forward by Lúcio Costa in his Pilot Plan Report, it has never been central. Second, the system is extremely dispersed, and this is characterised here by means of two alternative measures of compactness. Third, there is a strong sociospatial segregation, characterised by the weak correlations which obtain among localization of jobs, localization of homes, and physical accessibility: not only the great majority of jobs is also eccentric (for more than 70\% locate in the Pilot Plan), but also the great majority of inhabitants live in the most segregated bits of the city. At the end of the paper we discuss measures that imply a greater urbanity for the Federal Capital.

K E Y W O R D S Brasilia; centrality; compactness; social segregation; space syntax; urban design; urbanity. 